\title{
Introduction and Analysis of Environmental Geophysics
}

\author{
Lin Sun, Yanli Ding*, Junjie You and Xuefen Li \\ College of environmental science and engineering, Guilin University of Technology, Guilin, 541004,China
}

\begin{abstract}
Environmental geophysics,also known as the near surface geophysics,it is environmental science and Geophysics integration and a borderline subject developed,to study the relationship between geophysical field and matter in the earth's physical characteristics and the livingenvironment of mankind(including natural and artificial environment)using the theory and method of Geophysics, this relationship includes both the geophysical field of the human living environment and human health effects,including due to natural and anthropogenic environmenta-l changes in the earth material properties and geophysical field changes. At the same time, this subject has applications in the field of chrome plating, such as geophysical exploration, environmental monitoring, groundwater monitoring and so on. Today, geophysics has become a new subject with great potential application value.
\end{abstract}

\section{Introduction}

With the development of society economy,people to the environmental emissions and leakage of harmful substances than the degradation ability of nature, these pollutants remain in nature, a serious threat to the human survival and development. In order to solve the problem of environmental pollution, many subjects involved in the study of environmental pollution control,the environment of the earth physics is in such a large background. Environmental geophysics[1,2], also known as the near surface geophysics, it is environmental science and Geophysics integration and a borderline subject developed, to study the relationship between geophysical field and matter in the earth's physical characteristics and the living environment of mankind (including natural and artificial environment) using the theory and method of Geophysics, this relationship includes both the geophysical field of the human living environment and human health effects, including due to natural and anthropogenic environmental changes in the earth material properties and geophysical field changes. At the same time, this subject has applications in the field of chrome plating,such as geophysical exploration, environmental monitoring, groundwater monitoring and so on. Today, geophysics has become a new subject with great potential application value.

\section{The significance and application of the Geophysical purposes}

\subsection{Discipline significance}

Geophysics is one of the major disciplines of Earth Science,is through the quantitative physical methods (such as:seismic elastic wave, gravity, geomagnetism, geoelectricity and geothermal and radiation can method) to the study of the earth and looking for mineral resources of the earth interior is a comprehensive subject,the scope of the study include the earth's crust, mantle and core and atmosphere. Geophysics has many branches of study, including:solid earth physics, geodynamics, seismology, geodesy,geothermics,geomagnetism,hydrologicalgeograp -hy, oceanograph, meteorology,core tectonics and Geophysics[3],Comparative Planetology, Tectonophysics and geodetic astronomy; the content of the research includes the internal structure of the earth,theoretical source,seismic wave propagation theory, characteristics of continental crust in large scale, such as plate subduction zone and the mid ocean ridge. Traditional geophysics mainly refers to solid earth physics,the study of modern geophysics extends to the phenomenon of the earth's atmosphere.Such as ionospheric dynamo and auroral electrojets and magnetopause current system[4] and even extended to the physical properties of the planets and their satellites.

\subsection{Discipline application}

At present,the application of the earth physics:

1.Engaged in geological exploration,scientific research work as the main direction,through a variety of geophysical methods in geological research.

2.To predict natural disasters, the digital seismic network and station observation data as the basis, combined with gravity, deformation and other geophysical observation means, the kinematics and dynamics of the source, near fault ground motion and variation of gravity field of research,for the earthquake occurrence mechanism research and earthquake prediction to provide theoretical guidance.

3. Engaged in engineering exploration, by geophysical methods, exploration project, construction of hydrogeolo -gy and engineering geology, urban environment and building foundation and underground pipelines laying of exploration, through the theory of engineering geology, shallow geophysical and geotechnical mechanics,experim -entalresearch and engineering practice and information integration, understanding of earth surface material, the structure, the state and in natural and engineering under the action of deformation and failure mechanism and process and evaluation of engineering rock mass stability and environment effect.

4. For prospecting oil and natural gas and geological tectonic coalfields, looking for metal and nonmetal mine -ral resources, coal, oil field, mine property, stateowned large and mediumsized enterprises related technical work. 
5. The corresponding geophysical software programs are designed to do, geophysical instrument development, widely used in environmental protection, urban drainage, geology, metallurgy, health and epidemic prevention, commodity inspection, agriculture, fishery and education and scientific research fields[5].

\section{The purpose and significance of Envir- onmental Engineering}

\subsection{Discipline significance}

Environmental Engineering is a scientific and technologi -cal research and the prevention and control of enviro -nmental pollution and improve the quality of the environment. Environmental engineering and biology, ecology ,medicine and environmental hygiene and envir onmental medicine, and environmental physics and e nvironmental chemistry.Since environmental engineerin$\mathrm{g}$ is in the initial stage, the field of discipline is still $\mathrm{d}$ eveloping,but its core is the governance of environmental pollution sources.

\subsection{Discipline application}

Environmental monitoring is designed to realize the purpose of the past and predict the future by observing and analyzing the process of environmental change, understanding the environmental variable rate and its driving factors and mechanisms. So far,awareness of the issue of focus is still starting from the atmosphere,hydros -phere, pedosphere and lithosphere of some sensitive parameters for longterm observation and accumulation of work,summed up from the objective law of the environ -mental changes, concerning science,biology, agriculture and other disciplines[6].

\section{The combination of Environment and Geophysics}

Geophysics and environmental monitoring and protection exists between the dual relationship. On the one hand, geophysical field of energy flow to the earth's environme -nt and biology, including hasbrought a significant impact on the health of human body. On the other hand, geop -hysical exploration methods[7]can be used to monitor environmental pollution,resource damage,to carry out the prediction of disaster, and to provide information[8]for the design of environmental protection facilities. The scientific history shows that science has experienced a process of integration, differentiation and integration. Modern science is not only highly differentiated and highly integrated, but also set the integration of scientific and integrated differentiation and integration,to achieve the overall scientific. Put forward the idea of environme -ntal geophysics.

\section{Present situation and development pro -spect}

At present,the research and application of environmental geophysics mainly include[9]:

1.The influence of the physical field of the earth on the environment and the living world,especially to human he alth[10].

2.Monitoring of environmental pollution and its treatment process by geophysical method.

3.Using geophysical methods to monitor and forecast the damage and the disasters.

And in the next few years,the world wide engineering and environmental geophysics research work will be mainly concentrated in the following areas:[11]

1.Resistivity and electromagnetic wave imaging technolo -gy (including ground penetrating radar technology).

2.Surface wave exploration technology

3.Water and soil pollution monitoring survey technology

4.Environmental Remote Sensing Monitoring Technolog-

$\mathrm{y}$

5.Mine geophysical technology

6.Underwater exploration technology

7.Nuclear geophysical technology

8.Seismic disaster evaluation technique[12]

9.Environmental effects of the geophysical field(artificial and natural)

10.Efficient and practical exploration instrument system

\section{Application of environmental Geophysics}

\subsection{Environmental geophysical exploration}

Environmental geophysical exploration[13]is the basis of the study of the effect of the earth's physical environment. In general,the detection of various geophysical fields in geophysics can be used as a method of environmental geophysics observation[14]. Observation of the earth's gravity field, electromagnetic field, geothermal field, and intensity of radioactive radiation. These observations[15] are generally carried out on the ground or in the air or underground. Some observation requirements are not sati -sfied with the general geophysical observation, such as indoor oxygen content measurement, it is required to produce a higher sensitivity of specialized instruments. Borrow Applied Geophysics study observations to study the environmental effects, of course, is the economic, but with deep research, dedicated to environmental effects of the geophysical exploration investment will be more and more.

\subsection{Geophysical and environmental monitori -ng}

Examples of physical environment and engineering of the earth and the methods to solve the problems, the envir -onmental and engineering geophysical applications constantly expanding,covers construction,water resources and geothermal resources exploration[16], disaster evalu 
-ation and forecast, environmental pollution detection and monitoring, construction quality inspection, archaeologic -al research, the development and applications to ecologic -al agriculture, biological monitoring, more closely with people's daily life and national development together. On the existing problems of environmental and engineering geophysical exploration[17],many problems have been solved or to obtain specific ideas and methods to solve the problems, such as reservoir dam leakage, sandwich the detection problem, the tunnel wall forecast problems, active fault detection. Geophysical methods are mainly applied to the exploration of environmental pollution, which is a field of the development of geophysics. Water environmental geophysics is the theory, methods, geophy -sical technology into the hydrosphere,pollution monitoring. Water pollution not only reduces the available water resources, but also leads to a great harm to human health, therefore, the protection of water environment is not contaminated has become a very important work.

\subsection{The application of geophysical method in gro undwater monitoring.}

Today, the groundwater pollution is serious, Large and medium sized enterprise waste water discharge is one of the important causes of groundwater pollution, and it should be monitored by the dynamic monitoring of the pollution level and scope of the earth. Monitoring of pollutant composition ,need to identify the geological structure, determine the pollution channel, to control pollution sources,reduce pollution.Geophysical methods used to determine the scope of environmental pollution, both economic and rapid, but also to avoid drilling and water samples analysis, reduce pollution. At present, the degree of pollution in many underground water sources is mainly determined by the structure of the water bearing layer which is covered by the pollution. If the overburden faults are well developed or loose, then the industrial sewage and the living water will seep along the crack or the hole,causing the groundwater pollution. The application of geophysical methods can detect the structural characteristics of the overburden, the nature of the pollution channel, and the permeability of polluted water. On the other hand, it can monitor the speed and range of the pollution. Pollution of shallow water to the deep water, similar to the Shanghai deep water, ground back irrigation along the water channel to the undergroun -d leakage, resulting in deep water pollution[18], by geo -physical methods can be dynamic monitoring, to guide the governance.

\section{Summary and Outlook}

Currently less studies on the application of environmental geophysics, from the perspective of literature in recent years, few of its application in environmental monitoring and survey have more in depth inquiry, because of environmental monitoring and governance itself is not the economy benefit, resulting in the geophysics in enviro -nmental protection work in progress is slow. Should strengthen the research on electromagnetic imaging, surface wave exploration technology, remote sensing technology and mine geophysical technique, strengthen data processing combination of research methods and data acquisition equipment research, strengthen the combination of theoretical research and experimental research. To make geophysical method is better applied to environmental monitoring, environmental agencies and staff workers and Geophysics needs mutual cooperat -ion,actively coordinate with and strengthen the internatio -nal academic exchange and cooperation, disciplines to promote the sustained and in depth development,training physical talent of the earth's environment, to ensure the smooth progress of the research topic,for human science to make more contributions[19].

\section{Acknowledgements}

The work was funded by the National Natural Science Foundation of China (No.51408147,51168012,4140411

6) and Guangxi Natural Science Foundation (No.2014 GXNSFBA118234), Supported by the Research funds of The Guangxi Key Laboratory of Theory and Technol -ogy for Environmental Pollution Control (1401Z007)

\section{References}

[1] Gueli .S . Vakhromeev. Environmental geophysics: modern conception[J].Earth Science Frontiers. 2001, 8(1):47-57.

[2] Don W.Steeples, The Near-Surface Geophysics Sect i-on [J]. The Leading Edge, 1993, 12 (9):922 923

[3] Yonggui Zhao. Chinese Progress and future of Engi n-eering Geophysics [J]. The Progress in Geoph ysics,2002,17(2):305 309. (In Chinese)

[4] Gang Zhao. The application of magnetic prospecting and electrical prospecting in the detection area of $\mathrm{s}$ ponta-neous combustion [J]. Mineral exploration pro jects in West China, 2003(11): 63-64.(In Chinese)

[5] Sihai Wang.Introduction to the physical environment of the earth [J]. Geological Sciences, 2005 (03) : 23 -24.(In Chinese)

[6] Zhenglin Pei,On earth physics and modern hydrology, engineering and environmental geology,1999(02):40 2-405.(In Chinese)

[7] Xinqiu Chen. Xuzhou Peng. Geophysical detection a nd its application in special conditions[J]. The Progr ess in Geophysics, 2004,19 (4):880 882. (In Chines e)

[8] Linpei Cui.Geophysics and environmental monitoring and protection $[\mathrm{J}]$ Foreign exploration technology,1 995(02):222-223.(In Chinese)

[9] Haobin Dong, Chuanlei Wang. Development and app lication of high density resistivity method[J].Frontier Science,2003(1):171-176.(In Chinese)

[10]Hong Liu,Xingzhong Yuan.Geophysical environment and human health [J] Shanghai Environmental Sci ence vol,13 No.4 in April 1994.(In Chinese)

[11] Junxing Chao, Zhenghua He, Jieshou Zhu, Current situation and trend of development of engineering and environmental geophysics [J] Advances in Earth Science vol,13 No.5 in October 1998. (In Chinese) 
[12] Jiaying Wang, Chen Chao, Jianghai Xia. Progress in Environmental and Engineering Geophysics[J]. Proc eedi-ngs of the International Conference on Enviro nmental and Engineering Geophysics(ICEEG),Scien ce Press,2004.(In Chinese)

[13] Steve D.Environmental geophysics: What is needed to be successful [J].The Leading Edge,2002,21(1):6 $5 \sim 66$.

[14] Jin Yang. Environmental geophysics course [M]. B eijing:China University of Geosciences (Beijing),200 4,15(1):63-64.(In Chinese)

[15] Rong Zhao,Xiangyun Hu, Dikun Yang, el. Review on the development of nuclear magnetic resona nce technology [J]. The Progress in Geophysics,20 06,21(1):284 289.(In Chinese)

[16] Engineering and Environmental Geophysics for the 21st Century (Proceedings of the ISEEG'97). Sichu an Publishing House of Science and technology,199 7.

[17] Yonggui Zhao. The Research of Progress on the difficult problems in engineering geophysical detecti on [J]. The Progress in Geophysics, 2003, 18(3):36 8 369.(In Chinese)

[18] JinYang. Application of environmental geophysics method in groundwater pollution monitoring.(In Chi nese)

[19] Zhongquan Chao, Ping Xie, Hua Jin . Application of ground to ground in satellite borne synthetic a pert-ure radar[J].The Progress in Geophysics,2004,1 9(2):291 295.(In Chinese) 